\title{
Photodynamic Effects of Curcumin Against Cariogenic Pathogens
}

\author{
Natália Costa Araújo, M.D., Carla Raquel Fontana, Ph.D., ${ }^{2,3}$ Vanderlei Salvador Bagnato, Ph.D., ${ }^{3}$ \\ and Marleny Elizabeth Martinez Gerbi, Ph.D. ${ }^{1}$
}

\begin{abstract}
Background data: The presence of Streptococcus mutans and Lactobacillus acidophilus in dental structure is an indicator of a cariogenic biofilm. Photodynamic therapy is a technique that involves the activation of photosensitizers by light in the presence of oxygen, resulting in the production of reactive radicals capable of inducing cell death. Reduction of bacteria levels can provide additional means of preventing dental caries. Objective: The present study evaluated the susceptibility of planktonic cultures of S. mutans (ATCC 25175) and L. acidophilus (ATCC-IAL-523) from the Adolfo Lutz Institute (IAL) to photodynamic therapy after sensitization with curcumin and exposure to blue light at $450 \mathrm{~nm}$. Methods: Bacterial suspensions of S. mutans and L. acidophilus isolated (as single species) and combined (multspecies) were prepared and then evaluated. Four different groups were analyzed: L-D- (control group), L-D + (drug group), L+D- (light group), and L+D + (photodynamic therapy group). Two different concentrations of curcumin were tested $(0.75$ and $1.5 \mathrm{~g} / \mathrm{L})$ associated with a $5.7 \mathrm{~J} / \mathrm{cm}^{2}$ light emission diode. Results: Significant decreases $(p<0.05)$ in the viability of $S$. mutans were only observed when the bacterial suspensions were exposed to both curcumin and light. Then, reductions in viability of up to $99.99 \%$ were observed when using $1.5 \mathrm{~g} / \mathrm{L}$ of the photosensitizer. The susceptibility of L. acidophilus was considerably lower $(21 \%$ and $37.6 \%)$ for both curcumin concentrations. Conclusions: Photodynamic therapy was found to be effective in reducing S. mutans and L. acidophilus on planktonic cultures. No significant reduction was found for $\mathrm{L}-\mathrm{D}+$, proving the absence of dark toxicity of the drug.
\end{abstract}

\section{Introduction}

D ENTAL PLAQUe IS THE BIOFILM found naturally on teeth. It is implicated in dental caries, which is associated with shifts in the microbial balance of the biofilm, resulting in increased proportions of acid-producing and acid-tolerating bacteria, especially Streptococcus mutans and lactobacilli. ${ }^{1}$

S. mutans, gram-positive aerotolerant anaerobic bacteria, are considered the most cariogenic microorganisms in dental biofilm because of their capacity to use dietary carbohydrates to synthesize extracellular polysaccharides (EPS) and because of their acidogenic and aciduric properties. EPS are important virulence factors of $S$. mutans because they promote bacterial adherence to the tooth surface, which contributes to the structural integrity of dental biofilms and increases enamel demineralization. ${ }^{2,3}$

Various authors have identified species of lactobacilli found in carious tissues. ${ }^{4-7}$ Although the adhesive properties of lactobacilli are not remarkable, it has been shown that they were also able to adhere to various cell cultures involving a certain level of specificity. ${ }^{8}$ This specificity is related to the lactobacilli protein S-layer in the cell surfaces, which has a crystalline structure responsible for the surface hydrophobicity. This characteristic could promote the ability of the bacterial surface hydrophobicity to adapt to environmental changes. $^{8-11}$ The best known determinants of cariogenicity in lactobacilli are their capacity to produce acids and their ability to grow and survive in an acidic environment. ${ }^{12-15}$

The presence of $S$. mutans and Lactobacillus acidophilus in dental biofilm has been used as an indicator of cariogenic biofilm. Reducing the levels of these bacilli in the oral cavity will provide additional means for the prevention of dental caries. $^{16,17}$

Recently, alternatives that might offer the possibility for efficient reduction of cariogenic microorganisms and, consequently, make a feasible control of dental caries are being sought. ${ }^{18-21}$ Under these circumstances, photodynamic therapy (PDT) may be a possible new approach for caries treatment.

\footnotetext{
${ }^{1}$ Dental School of Pernambuco, University of Pernambuco, Camaragibe, Brazil.

${ }^{2}$ Department of Clinical Analysis, School of Pharmaceutical Sciences, University of São Paulo State (UNESP), Araraquara, Brazil.

${ }^{3}$ Institute of Physics of São Carlos, University of São Paulo (USP), São Carlos, Brazil.
} 
PDT is based on the principle that a photoactivatable substance (the photosensitizer) is bound to the target cell and can be activated by light of a suitable wavelength. During this process, oxygen species, such as singlet oxygen and free radicals, are formed, which then produce an effect that is toxic to the cell. To have a specific toxic effect on bacterial cells, the respective photosensitizer needs to be selective for certain prokaryotic cells. By irradiation with light in the visible range of the spectrum, the photosensitizer is excited to its triplet state, and the energy is transferred to the molecular oxygen. Highly reactive singlet oxygen capable of reacting with biological systems and destroying them is formed. ${ }^{22,23}$ PDT represents an alternative antibacterial, antifungal, and antiviral treatment for drug-resistant organisms. ${ }^{24-28}$ It is not likely that bacteria would develop a resistance to the cytotoxic action of singlet oxygen or free radicals. ${ }^{24}$

PDT might be an excellent alternative to decrease the population of cariogenic microorganisms and to control dental caries. The relative simplicity of the mechanism to activate photosensitizers has led to a considerable interest in this therapeutic method. The effectiveness of PDT against oral bacteria has been the subject of several studies. ${ }^{26,27,29,30}$ However, none of those studies used curcumin as a photosensitizer to kill cariogenic bacteria.

Curcumin, a compound isolated from Curcuma longa L., has been used for centuries as a medicine, a dietary pigment, and as a spice. The drug has a variety of traditional pharmaceutical applications, ${ }^{31,32}$ including treatment of liver diseases, wounds, and inflamed joints, as well as for blood purification and microbial effects. ${ }^{33}$ Curcumin has proven nontoxic in a number of cell cultures and animal studies. It has a rather broad absorption peak in the $300-500 \mathrm{~nm}$ range (maximum $\sim 430 \mathrm{~nm}$ ) and exerts potent phototoxic effects in micromolar amounts. Therefore, curcumin has the potential for use as a photosensitizer for treatment of localized superficial infections in the mouth or on the skin. ${ }^{34-37}$

The objective of the present study was to evaluate the photodynamic effects of curcumin on planktonic cultures of S. mutans and L. acidophilus using a blue light emitting diode (LED) with a central wavelength of $450 \mathrm{~nm}$ and curcumin as a photosensitizer. We also evaluated the synergism of both pathogens when they had been exposed to photodynamic inactivation.

\section{Materials and Methods}

\section{Photosensitizer}

A curcumin salt prepared by PDT-Pharma (Cravinhos, $\mathrm{SP}$, Brazil) was dissolved in sterile distilled water to get solutions at concentrations of 0.75 and $1.5 \mathrm{~g} / \mathrm{L}$.

The ultraviolet-visible (UV-Vis) absorption spectra of this solution were recorded from 300 to $700 \mathrm{~nm}$ using quartz cuvettes with a $1 \mathrm{~cm}$ path length on a Cary 50 Bio UV-Vis spectrometer (Varian, Darmstadt, Germany), and they were characterized by a long wavelength maximum at $430 \mathrm{~nm}$ (Fig. 1).

\section{Light source}

A blue LED (Edixeon ${ }^{\circledR}$, Edison Opto Corporation, New Taipei City, Taiwan) with an intensity of $19 \mathrm{~mW} / \mathrm{cm}^{2}$ (real intensity in the solution for each well and $\sim 6 \%$ of plastic

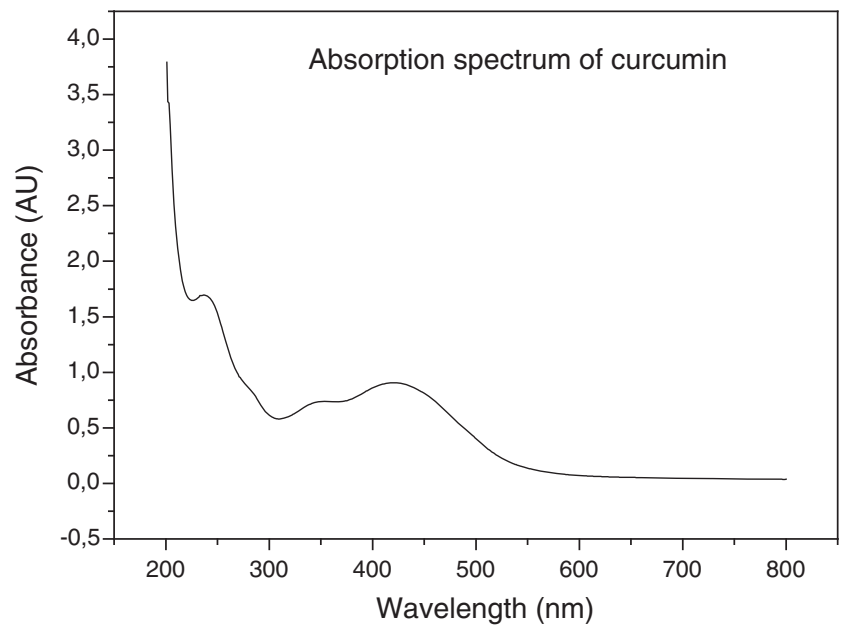

FIG. 1. Curcumin ultraviolet-visible absorption spectra.

absorption of light already deducted), a central wavelength of $450 \mathrm{~nm}$, and an estimated average fluency of $5.7 \mathrm{~J} / \mathrm{cm}^{2}$ was used. The system, which is composed of 96 LEDs, is able to uniformly deliver irradiation without causing a heating effect (because of the presence of a cooler on the sides). The distance between the LED and the plate was designed to evenly distribute the light on each well, and all the internal surfaces were mirrored (Fig. 2). The power density of the incident radiation was measured using a power meter $(\mathrm{Co}-$ herent ${ }^{\circledR}$, Santa Clara, CA).

\section{Microorganisms}

Two common cariogenic pathogens were used in this study: S. mutans (ATCC25175) and L. acidophilus (ATCC\#ITAL-523). Cultures of these bacterial species were kept as weekly subcultures in blood agar plates. An enriched agar medium was prepared containing $20 \mathrm{~g} / \mathrm{L}$ of trypticase soy agar (Oxoid LTD, Basingstoke, Hampshire, England), 26 g/L

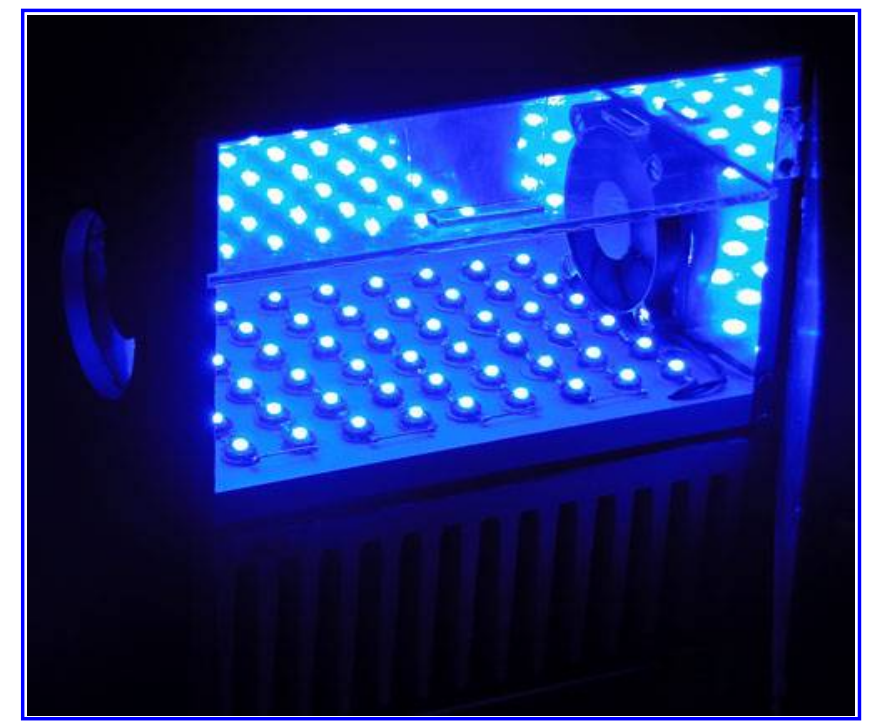

FIG. 2. Light system with 96 LEDs delivering a uniform radiation (mirrored device) with coolers to avoid heating effect. 
of brain-heart infusion agar (Oxoid LTD, Basingstoke, Hampshire, England), $10 \mathrm{~g} / \mathrm{L}$ of yeast extract (BBL), and $5 \mathrm{mg} / \mathrm{L}$ of hemin (Sigma Chemical Co., St. Louis, MO). The medium was autoclaved and cooled down to $50^{\circ} \mathrm{C}$. Then, $5 \%$ defibrinated sheep blood (NewProv LTDA, Pinhais PR, Brazil) and $5 \mathrm{mg} / \mathrm{mL}$ of menadione (Sigma Chemical Co.) were added under aseptic conditions. For experimental purposes, organisms were grown under microaerophilic conditions for $48 \mathrm{~h}$ at $36+-1^{\circ} \mathrm{C}$ and resuspended in a brainheart infusion (BHI) broth. The cells were dispersed in the BHI broth by vortexing and by a repeated passage through Pasteur pipettes. The cell numbers were measured by means of a spectrophotometer (wavelength, $600 \mathrm{~nm} ; 0.1$ optical density unit equals $\sim 10^{8}$ cells $/ \mathrm{mL}$ ) in $1 \mathrm{~mL}$ cuvettes.

\section{BDT of bacterial suspensions}

S. mutans and L. acidophilus bacterial suspensions were prepared and the following groups were formed: Group LD-: no light, no drug; Group L-D+: treated only with drug (curcumin); Group L+D-: treated only with light; and Group $\mathrm{L}+\mathrm{D}+$ : treated with curcumin and light (PDT group).

Sterile containers with $35 \mathrm{~mL}$ of bacterial suspensions $\left(10^{8} /\right.$ $\mathrm{mL}$ ) were vortexed for $2 \mathrm{~min}$ to disperse the cells. Then, $100 \mu \mathrm{L}$ of culture aliquots and $100 \mu \mathrm{L}$ of curcumin solution were placed in the wells of 96-well plates for $5 \mathrm{~min}$ before they were exposed to light (incubation time). After drug incubation, the plates were placed in special equipment (see Fig. 2) where only blue light was delivered for $5 \mathrm{~min}$. The final drug concentrations used were 0.75 and $1.5 \mathrm{~g} / \mathrm{L}$; however, when $100 \mu \mathrm{L}$ of curcumin solution was added at culture aliquots $(100 \mu \mathrm{L})$, each curcumin concentration was adjusted $(1.5$ and $3.0 \mathrm{~g} / \mathrm{L})$ to have the final solution of 0.75 and $1.5 \mathrm{~g} / \mathrm{L}$.

The light exposure was done from below with an irradiance of $19 \mathrm{~mW} / \mathrm{cm}^{2}$ for each well and a fluence of $5.7 \mathrm{~J} / \mathrm{cm}^{2}$. All plates were kept closed using fitted polystyrene lids to maintain the sterility of the culture during the illumination, and the plastic absorption of the light was deducted. After illuminating the appropriate wells, serial dilutions of the contents of each well were prepared in BHI broth, and $100 \mu \mathrm{L}$ aliquots were spread over the surfaces of the blood agar plates and then incubated under microaerophilic conditions for $72 \mathrm{~h}$.

Groups L-D- and L-D+ were kept in the plates at room temperature in the dark, covered with aluminum foil, for the same time as the irradiation time, and Group L+D- was irradiated with blue light from the diode laser for $5 \mathrm{~min}$ at room temperature in the absence of the drug. Three wells per group were used in each experiment and three repetitions were performed.

\section{Statistical analysis}

The Statistical Package for Social Sciences (SPSS, Chicago, IL, 2006), version 13.0, was used to process the data. Differences between means were analyzed for statistical significance by one-way ANOVA. The Tukey test was chosen to evaluate the significance of all pairwise comparisons with a significance limit of $5 \%$.

\section{Results}

The data are reported as the mean of a triplicate measurement. Survival fractions in each well were calculated by

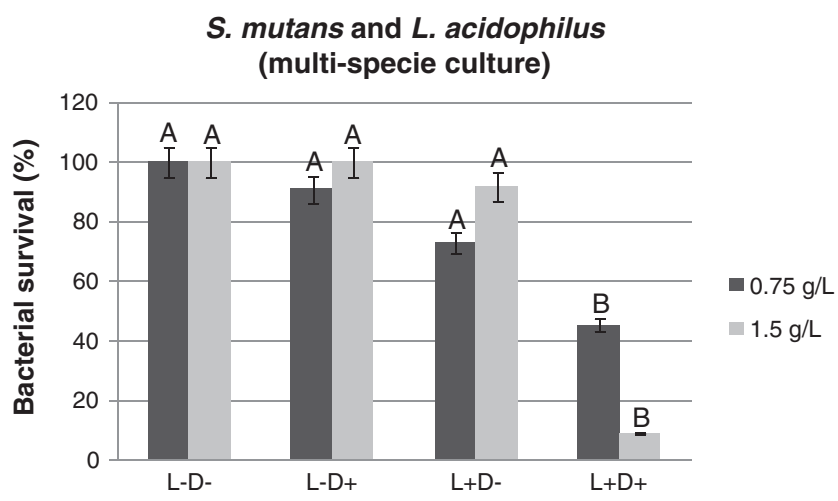

FIG. 3. Streptococcus mutans and Lactobacillus acidophilus (multispecies culture) survival of studied groups after photosensitization with 0.75 and $1.5 \mathrm{~g} / \mathrm{L}$ of curcumin followed by irradiation with blue light at a wavelength of $450 \mathrm{~nm}$. Same letter (A) means no significant difference among the groups $(p>0.05)$.

counting the colonies on the plates $(\mathrm{L}+\mathrm{D}+)$ and dividing these by the number of colonies from the control group (L-D-).

The effects of PDT on planktonic cultures of S. mutans and L. acidophilus can be seen in Fig. 3, and show that the group that used curcumin followed by blue light illumination $(\mathrm{L}+\mathrm{D}+)$ contained a significantly lower number of bacteria $(p<0.05)$ than did any other group. Reductions of $54 \%$ and $91 \%$ were obtained for 0.75 and $1.5 \mathrm{~g} / \mathrm{L}$, respectively. Differences among mean survival fractions for the other groups were quite low.

Figure 4 shows the effect of the exposure of the S. mutans suspension to $0.75 \mathrm{~g} / \mathrm{L}$ curcumin and subsequent illumination with light, resulting in a $68 \%$ reduction $(p<0.05)$ of viable cells. When the curcumin concentration was $1.5 \mathrm{~g} / \mathrm{L}$, a decrease of $100 \%$ for the bacterial survival fraction was obtained $(p<0.05)$.

A small reduction of $21 \%$ was observed when $L$. acidophilus suspension was exposed to $0.75 \mathrm{~g} / \mathrm{L}$ curcumin and subsequently illuminated with light $(p>0.05)$. However, at a curcumin concentration of $1.5 \mathrm{~g} / \mathrm{L}$, a slightly higher reduction of $37.6 \%(p<0.05)$ was observed (Fig. 5). Moreover, the

\section{S. mutans (single-specie culture)}

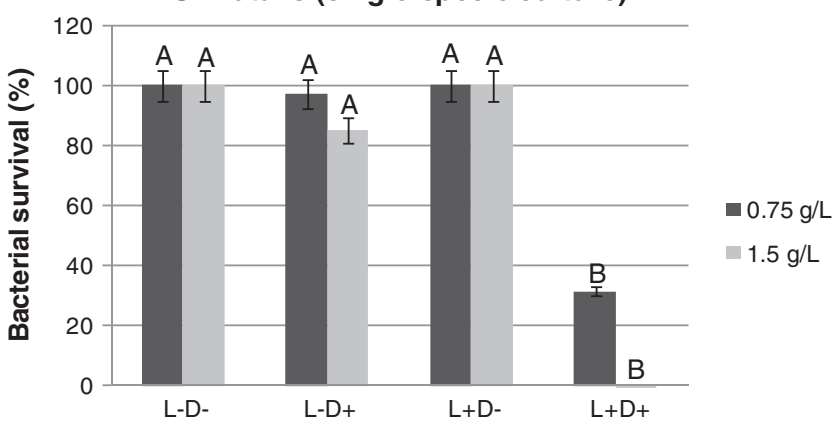

FIG. 4. Streptococcus mutans (single species culture) survival of studied groups after photosensitization with $0.75 \mathrm{~g} / \mathrm{L}$ and $1.5 \mathrm{~g} / \mathrm{L}$ of curcumin followed by irradiation with blue light at a wavelength of $450 \mathrm{~nm}$. Same letter (A) means no significant difference among the groups $(p>0.05)$. 


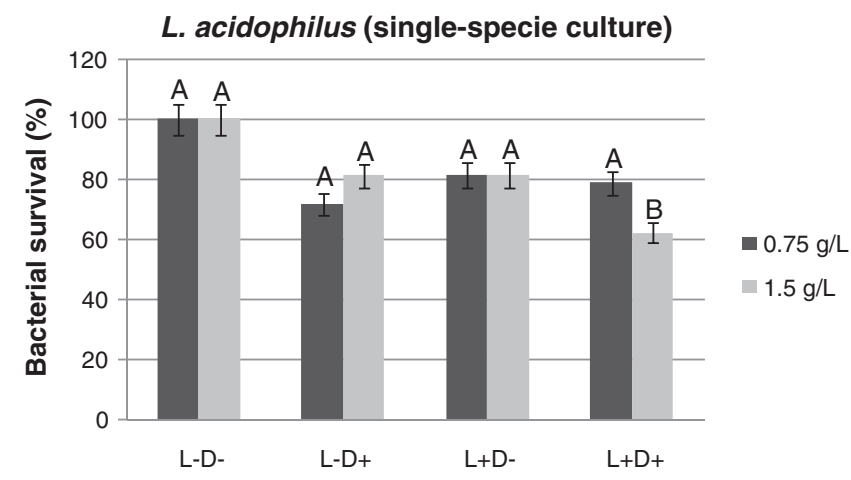

FIG. 5. Lactobacillus acidophilus (single species culture) survival of studied groups after photosensitization with 0.75 and $1.5 \mathrm{~g} / \mathrm{L}$ of curcumin followed by irradiation with blue light at a wavelength of $450 \mathrm{~nm}$. Same letter (A) means no significant difference among the groups $(p>0.05)$.

photodynamic effect was dose dependent for the curcumin concentration, as shown in Fig. 6.

In the dark toxicity assays (L-D+), it was demonstrated that, for the concentrations tested, curcumin does not show toxicity for all planktonic cultures. It was also observed that, without curcumin, light irradiation alone (L+D-) did not affect the viability of the microorganisms.

\section{Discussion}

Numerous studies have demonstrated the success of PDT against oral bacteria, ${ }^{26,27,29-32}$ but none of these studies evaluated the susceptibility of $S$. mutans and L. acidophilus to PDT using curcumin as a photosensitizer. The results of this study show that curcumin in combination with blue light had a phototoxic effect on S. mutans and L. acidophilus. Similar results have been shown in previous studies using different photosensitizers on oral bacteria. ${ }^{38-41}$
One of the main observations made during the first tests to photoinactivate bacteria with conventional photosensitizers was the relative sensitivity of gram-positive strains to photodynamic inactivation. ${ }^{24}$ This sensitivity was confirmed in our study. Additionally, we observed that the photodynamic effect was dose dependent for different curcumin concentrations (Fig. 6). Bacterial reductions of $68.37 \%$ and $99.91 \%$ were obtained for S. mutans and reductions of $20.96 \%$ and $37.61 \%$ were obtained for L. acidophilus when curcumin was used at 0.75 and $1.5 \mathrm{~g} / \mathrm{L}$, respectively.

For single species of S. mutans, total elimination with $100 \%$ efficacy was obtained with curcumin at $1.5 \mathrm{~g} / \mathrm{L}$ after irradiation with blue light (Fig. 4). Despite the achieved reduction $(p<0.05)$ of L. acidophilus, under the same assay conditions as for S. mutans, PDT had a lower effect on cell viability (Fig. 5). L. acidophilus, tested as a single species and using the same concentrations of curcumin, was less susceptible to PDT than was S. mutans.

Exposure to oxygen has a profound effect on the phenotypic properties of $S$. mutans, which in turn directly impact the virulence of this pathogen. ${ }^{42}$ According to Ahn and Burne, ${ }^{43}$ exposure of $S$. mutans to oxygen inhibits a biofilm formation on polystyrene surfaces and induces changes in the cell surface protein profiles. Exhibiting distinctive phenotypic properties, the organisms tend to react differently to antimicrobial agents or to photosensitizer drugs. The oxygen modulates the expression of a variety of genes in S. mutans, many of which participate in the formation of a biofilm or can contribute to virulence in some other way. ${ }^{44}$

It is known that during photodynamic inactivation, a number of reactive oxygen species (ROS) are generated. S. mutans responds to environmental stresses caused by oxidation, heat, acidity, and salinity or by specific or coordinated regulations of the protein levels. ${ }^{45}$ Different forms of life, macroscopic or microscopic, respond to oxidative stress in very similar ways, mainly by trying to neutralize free radicals through enzymes with catabolic activity. The success

\section{Photodynamic effect dose-dependent}

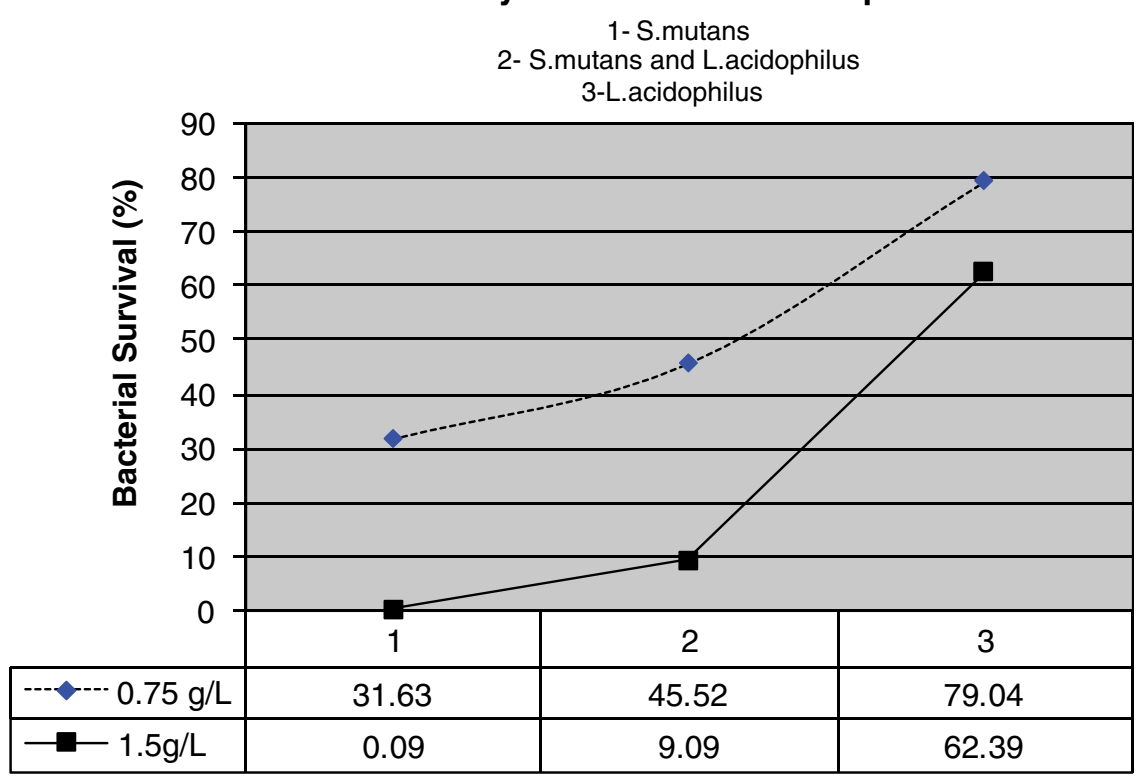

FIG. 6. The photodynamic effect was dose dependent of the curcumin concentration for all microorganisms tested. 
of this approach varies according to microbial genomic contribution and physiological state.

S. mutans lack cytochromes and catalase, the production of which is an inherent feature of the species when in an aerobic environment. However, S. mutans have facultative behavior, thanks to Nox1 and Nox2 genes that codify NADH oxidases $^{46}$ and possess other antioxidant enzymes, such as superoxide dismutase (SOD) and other peroxidases, which undergo a significant enhancement upon oxygen exposure of the bacterium. The superoxide anion is usually neutralized by the enzyme superoxide dismutase, produced by S. mutans and other oral streptococci. ${ }^{47}$ However, even though they have complex defense mechanisms that protect $S$. mutans against injuries to which it is habitually exposed in the oral cavity, according to our results, these mechanisms were not effective for their survival against the stress induced by PDT.

The regulation of SOD activity in bacterial cells is very complex. We can hypothesize that oxidative stress-associated toxicity is a result of cell wall and bacterial membrane damage, which leads to loss of cell viability. ${ }^{48}$ In our study, we can speculate that apart from the singlet oxygen and the superoxide anion, other ROS may have been generated during the photosensitizer-mediated photodynamic processes, which could affect the SOD regulatory pathways.

However, the lower photodynamic effects of the photosensitizer on the lactobacilli were probably affected by the presence of serum proteins in the BHI broth. ${ }^{26,49-51}$ In the present study, curcumin was dissolved in BHI broth, because proteins from both saliva and gingival crevicular fluid would also reduce the effect of the photosensitizer in the hypothetical case of its in vivo application. ${ }^{26}$

The use of the drug alone (L-D +) or the light alone ( $\mathrm{L}+\mathrm{D}-)$ did not lead to a significant reduction in the colony-forming unit (CFU) count $(p>0.05)$ of any of the microorganisms. A significant reduction of single species of L. acidophilus and $S$. mutans and for a combination of both only occurred when PDT was applied $(\mathrm{L}+\mathrm{D}+)$. Our findings corroborate those of other studies aimed at reducing microbial activity by using PDT. ${ }^{27,29,31,32,52}$

As the primary odontopathogen present in the supragingival plaque, $S$. mutans is closely related to enamel caries. Lactobacilli generally colonize after $S$. mutans have exposed the dentino-enamel interface, and they are often cultured from established carious lesions. Consequently, patients with low S. mutans population levels in their oral cavities generally have low caries activity. ${ }^{53}$

Caries reduction, therefore, has still to be balanced against increasing primary pathogen colonization by organisms such as S. mutans. ${ }^{54}$ Our investigation into the efficacy of PDT on planktonic cultures of S. mutans and L. acidophilus showed that PDT can kill cariogenic pathogens. Under certain conditions, it was possible to completely kill $S$. mutans and reduce L. acidophilus.

It has been known that bacteria within biofilms are more resistant to antimicrobial therapy ${ }^{29,55-58}$ than are microorganisms in an isolation planktonic environment. However, the selectivity of $S$. mutans reduction observed here in the planktonic phase may recommend curcumin as a photosensitizer, establishing PDT as one of the strategies for caries treatment and prevention.

Moreover, our results presented different vulnerability for PDT when microorganisms were in multiple or single spe- cies. Further investigation is also prompted by the surprising results of experiments with $L$. acidophilus, which showed more resistance to PDT than did S. mutans. In this way, studies will be conducted also in biofilms to clarify the required parameters. The results achieved in this study were the first step toward identifying the susceptibility of these pathogens to curcumin-based photodynamic therapy.

\section{Conclusions}

In conclusion, the results of this study showed that $S$. mutans and L. acidophilus were both susceptible to curcumin in the presence of blue light, but to a different extent. The results of this study suggest that the technique described may be useful for treatment of caries-related diseases, especially when an S. mutans reduction must be achieved.

\section{Acknowledgment}

Financial support from the Research Support Foundation of São Paulo State (FAPESP) and the Science and Technology Support Foundation of Pernambuco State (FACEPE) were provided.

\section{Author Disclosure Statement}

No competing financial interests exist.

\section{References}

1. Marsh, P.D. (2010). Microbiology of dental plaque biofilms and their role in oral health and caries. Dent. Clin. North Am. 54, 441-454.

2. Koo, H., Xiao, J., and Klein, M.I. (2009). Extracellular Polysaccharides matrix - An often forgotten virulence factor in oral biofilm research. Int. J. Oral Sci. 1, 229-234.

3. Xiao, J., and Koo, H. (2010). Structural organization and dynamics of exopolysaccharide matrix and microcolonies formation by Streptococcus mutans in biofilms. J. Appl. Microbiol. 108, 2103-2113.

4. Munson, M.A., Banerjee, A., Watson, T.F., and Wade, W.G. (2004). Molecular analysis of the microflora associated with dental caries. J. Clin. Microbiol. 42, 3023-3029.

5. Chhour, K.L., Nadkarni, M.A., Byun, R., Martin, F.E., Jacques, N.A., and Hunter, N. (2005). Molecular analysis of microbial diversity in advanced caries. J. Clin. Microbiol. 43, 843-849.

6. Martin, F.E., Nadkarni, M.A., Jacques, N.A., and Hunter, N. (2002). Quantitative microbiological study of human carious dentine by culture and real-time PCR: association of anaerobes with histopathological changes in chronic pulpitis. I. Clin. Microbiol. 40, 1698-1704.

7. Byun, R., Nadkarni, M.A., Chhour, K.L., Martin, F.E., Jacques, N.A., and Hunter, N. (2004). Quantitative analysis of diverse Lactobacillus species present in advanced dental caries. J. Clin. Microbiol. 42, 3128-3136.

8. Vadillo-Rodriguez, V., Busscher, H.J., van der Mei, H.C., de Vries, J., and Norde, W. (2005). Role of Lactobacillus cell surface hydrophobicity as probed by AFM in adhesion to surfaces at low and high ionic strength. Colloids Surf. B. Biointerfaces 41, 33-41.

9. Colloca, M.E., Ahumada, M.C., Lopez, M.E., and NaderMacias, M.E. (2000). Surface properties of lactobacilli isolated from healthy subjects. Oral Dis. 6, 227-233. 
10. Lipinski, T., Jones, C., Lemercinier, X., et al. (2003). Structural analysis of the Lactobacillus rhamnosus strain KL37C exopolysaccharide. Carbohydr. Res. 338, 605-609.

11. Harding, L.P., Marshall, V.M., Hernandez, Y., et al. (2005). Structural characterization of a highly branched exopolysaccharide produced by Lactobacillus delbrueckii subsp. bulgaricus NCFB2074. Carbohydr. Res. 340, 1107-1111.

12. Badet, C., and Thebaud., N.B. (2008). Ecology of lactobacilli in the oral cavity: a review of literature. Open Microbiol. J. 2, 38-48.

13. Badet, M.C., Richard, B., and Dorignac, G. (2001). An in vitro study of the $\mathrm{pH}$ lowering potential of salivary lactobacilli associated with dental caries. J. Appl. Microbiol. 90, 10151018.

14. Harper, D.S., and Loesche, W.J. (1984). Growth and acid tolerance of human dental plaque bacteria. Arch. Oral Biol. $29,843-848$.

15. Svensater, G., Larsson, U.B., Greif, E.C., Cvitkovitch, D.G., and Hamilton, I.R. (1997). Acid tolerance response and survival by oral bacteria. Oral Microbiol. Immunol. 12, 266-273.

16. de Soet, J.J., Nyvad, B., and Kilian, M. (2000). Strain-related acid production by oral streptococci. Caries Res. 34, 486-490.

17. Mattos-Graner, R.O., Smith, D.J., King, W.F., and Mayer, M.P. (2000). Water-insoluble glucan synthesis by mutans streptococcal strains correlates with caries incidence in 12- to 30-month-old children. J. Dent. Res. 79, 1371-1377.

18. Ramalingam, K., Amaechi, B.T., Ralph, R.H., and Lee, V.A. (2012). Antimicrobial activity of nanoemulsion on cariogenic planktonic and biofilm organisms. Arch. Oral Biol. 57, 15-22.

19. Tao, R., Tong, Z., Lin, Y., et al. (2011). Antimicrobial and antibiofilm activity of pleurocidin against cariogenic microorganisms. Peptides 32, 1748-1754.

20. Fagrell, T.G., Dietz, W., Lingström, P., Steiniger, F., and Norén, J.G. (2008). Effect of ozone treatment on different cariogenic microorganisms in vitro. Swed. Dent. J. 32, 139147.

21. Shi, W., Li, Y.H., Liu, F., et al. (2012). Flagellin enhances saliva IgA response and protection of anti-caries DNA vaccine. J. Dent. Res. 91, 249-254.

22. Al-Watban, F.A., and Zhang, X.Y. (2005). Photodynamic therapy of human undifferentiated thyroid carcinomabearing nude mice using topical 5-aminolevulinic acid. Photomed. Laser Surg. 23, 206-211.

23. O'neill, J.F., Hope, C.K., and Wilson, M. (2002). Oral bacteria in multi-species biofilms can be killed by red light in the presence of toluidine blue. Lasers Surg. Med. 31, 86-90.

24. Hamblin, M.R., and Hasan, T. (2004). Photodynamic therapy: a new antimicrobial approach to infectious disease? Photochem. Photobiol. Sci. 3, 436-450.

25. Meisel, P., and Kocher, T. (2005). Photodynamic therapy for periodontal diseases: state of the art. J. Photochem. Photobiol. B. 79, 159-170.

26. Komerik, N., and MacRobert, A.J. (2006). Photodynamic therapy as an alternative antimicrobial modality for oral infections. J. Environ. Pathol. Toxicol. Oncol. 25, 487-504.

27. Wood, S., Metcalf, D., Devine, D., and Robinson, C. (2006). Erythrosine is a potential photosensitizer for the photodynamic therapy of oral plaque biofilms. J. Antimicrob. Chemother. 57, 680-684.

28. Donnelly, R.F., McCarron, P.A., Tunney, M.M., and Woolfson, D. (2007). A potential of photodynamic therapy in treatment of fungal infections of the mouth. Design and characterisation of a mucoadhesive patch containing toluidine blue O. J. Photochem. Photobiol. B. 86, 59-69.
29. Fontana, C.R., Abernethy, A.D., Som, S., et al. (2009). The antibacterial effect of photodynamic therapy in dental plaque-derived biofilms. J. Periodontal. Res. 44, 751-759.

30. Metcalf, D., Robinson, C., Devine, D., and Wood, S. (2006). Enhancement of erythrosine-mediated photodynamic therapy of Streptococcus mutans biofilms by light fractionation. J. Antimicrob. Chemother. 58, 190-192.

31. Hegge AB, Andersen T, Melvik JE, Kristensen S, and Tønnesen HH. (2010). Evaluation of novel alginate foams as drug delivery systems in antimicrobial photodynamic therapy (aPDT) of infected wounds-an in vitro study: studies on curcumin and curcuminoides XL. J Pharm Sci. 99, 3499-3513.

32. Crivello, J. V., and Bulut, U. (2005) Curcumin: a naturally occurring long-wavelength photosensitizer for diaryliodonium salts. I Polym Sci A Polym Chem. 43, 5217-5231.

33. Aggarwal, B.B., Sundaram, C., Malani, N., and Ichikawa, H. (2007). Curcumin: the Indian solid gold. Adv. Exp. Med. Biol. 595, 1-75.

34. Haukvik, T., Bruzell, E., Kristensen, S., and Tønnesen, H.H. (2010). Photokilling of bacteria by curcumin in selected polyethylene glycol 400 (PEG 400) preparations. Studies on curcumin and curcuminoids, XLI. Pharmazie 65, 600-606.

35. Bruzell, E.M., Morisbak, E., and Tønnessen, H.H. (2005). Studies on curcumin and curcuminoids. XXIX. Photoinduced cytotoxicity of curcumin in selected aqueous preparations. Photochem. Photobiol. Sci. 4, 523-530.

36. Park, K., and Lee, J.H. (2007). Photosensitizer effect of curcumin on UVB-irradiated HaCaT cells through activation of caspase pathways. Oncol. Rep. 17, 537-540.

37. Dovigo, L.N., Pavarina, A.C., Ribeiro, A.P., et al. (2011). Investigation of the photodynamic effects of curcumin against candida albicans. Photochem. Photobiol. 87, 895-903.

38. Costa, A.C., Chibebe Junior, J., Pereira, C.A., et al. (2010). Susceptibility of planktonic cultures of Streptococcus mutans to photodynamic therapy with a light-emitting diode. Braz. Oral Res. 24, 413-418.

39. Bonstein, T., Mikulski, L.M., Bush, M.A., and Bush, P.J. (2010). Photoactivated disinfection of Streptococcus intermedius through dentin disc at clinically relevant intervals: an in vitro study. Arch. Oral Biol. 55, 771-777.

40. Lima, J.P., Sampaio de Melo, M.A., Borges, F.M., et al. (2009). Evaluation of the antimicrobial effect of photodynamic antimicrobial therapy in an in situ model of dentine caries. Eur. J. Oral Sci. 117, 568-574.

41. Giusti, J.S., Santos-Pinto, L., Pizzolito, A.C., et al. (2008) Antimicrobial photodynamic action on dentin using a lightemitting diode light source. Photomed. Laser Surg. 26, 281287.

42. Ahn, S.J., Ahn, S.J., Browngardt, C.M., and Burne, R.A. (2009). Changes in biochemical and phenotypic properties of Streptococcus mutans during growth with aeration. Appl. Environ. Microbiol. 75, 2517-2527.

43. Ahn, S.J., and Burne, R.A. (2007). Effects of oxygen on biofilm formation and the AtlA autolysin of Streptococcus mutans. J. Bacteriol. 189, 6293-6302.

44. Ahn, S.J., Wen, Z.T., and Burne, R.A. (2007). Effects of oxygen on virulence traits of Streptococcus mutans. J. Bacteriol. 189, 8519-8527.

45. Li, Y.H., Hanna, M.N., Svensater, G., Ellen, R.P., and Cvitkovitch, D.G. (2001). Cell density modulates acid adaptation in Streptococcus mutans: implications for survival in biofilms. J Bacteriol. 183, 6875-6884.

46. Higuchi, M., Yamamoto, Y., and Kamio, Y. (2000). Molecular biology of oxigen tolerance in lactic acid bacteria: Functions 
of NADH oxidases and Dpr in oxidative stress. J. Biosci. Bioeng. 90, 484-493.

47. Loo, C.Y., Mitrakul, K., Jaafar, S., Gyurko, C., Hughes, C.V., and Ganeshkumar, N. (2004). Role of a nosX homolog in Streptococcus gordoniiin aerobic growth and biofilm formation. J. Bacteriol. 186, 8193-8206.

48. Karavolos, M.H., Horsburgh, M.J., Ingham, E., and Foster, S.J. (2003). Role and regulation of the superoxide dismutases of Staphylococcus aureus. Microbiology 149, 2749-2758.

49. Bhatti, M., MacRobert, A., Meghji, S., Henderson, B., and Wilson, M. (1997). Effect of dosimetric and physiological factors on the lethal photosensitization of Porphyromonas gingivalis in vitro. Photochem. Photobiol. 65, 1026-1031.

50. Soukos, N.S., Mulholland, S.E., Socransky, S.S., and Doukas, A.G. (2003). Photodestruction of human dental plaque bacteria: enhancement of the photodynamic effect by photomechanical waves in an oral biofilm model. Lasers Surg. Med. 33, 161-168.

51. Foschi, F., Fontana, C.R., Ruggiero, K., et al. (2007). Photodynamic inactivation of Enterococcus faecalis in dental root canals in vitro. Lasers Surg. Med. 39, 782-787.

52. Williams, J.A., Pearson, G.J., Colles, M.J., and Wilson, M. (2004). The photo-activated antibacterial action of toluidine blue $\mathrm{O}$ in a collagen matrix and in carious dentine. Caries Res. 38, 530-536.

53. Fejerskov, O. (2004). Changing paradigms in concepts on dental caries: consequences for oral health care. Caries Res. 38, 182-191.
54. Senadheera, D., and Cvitkovitch, D.G. (2008). Quorum sensing and biofilm formation by Streptococcus mutans. Adv. Exp. Med. Biol. 631, 178-188.

55. Costerton, J.W., Stewart, P.S., and Greenberg, E.P. (1999). Bacterial biofilms: a common cause of persistent infections. Science 284, 1318-1322.

56. Zanin, I.C., Gonçalves, R.B., Junior, A.B., Hope, C.K., and Pratten, J. (2005). Susceptibility of Streptococcus mutans biofilms to photodynamic therapy: an in vitro study. J. Antimicrob. Chemother. 56, 324-330.

57. Konopka, K., and Goslinski, T. (2007). Photodynamic therapy in dentistry. J. Dent. Res. 86, 694-707. Erratum in: J. Dent. Res. 86, 1126.

58. Pereira, C.A., Romeiro, R.L., Costa, A.C., Machado, A.K., Junqueira, J.C., and Jorge, A.O. (2011). Susceptibility of Candida albicans, Staphylococcus aureus, and Streptococcus mutans biofilms to photodynamic inactivation: an in vitro study. Lasers Med. Sci. 26, 341-348.

Address correspondence to: Natália Costa Araújo

57 Dom Sebastião Leme Street Recife, PE 52011-160.

Brazil

E-mail: nataliacosta84@yahoo.com.br 
This article has been cited by:

1. Surya Prakash Singh, Mrinalini Sharma, Pradeep Kumar Gupta. 2013. Enhancement of phototoxicity of curcumin in human oral cancer cells using silica nanoparticles as delivery vehicle. Lasers in Medical Science . [CrossRef]

2. N. C. Araújo, C. R. Fontana, V. S. Bagnato, M. E. M. Gerbi. 2013. Photodynamic antimicrobial therapy of curcumin in biofilms and carious dentine. Lasers in Medical Science . [CrossRef]

3. Ping Hu, Ping Huang, Min Wei Chen. 2013. Curcumin reduces Streptococcus mutans biofilm formation by inhibiting sortase A activity. Archives of Oral Biology . [CrossRef]

4. August Bernd. 2013. Visible light and/or UVA offer a strong amplification of the anti-tumor effect of curcumin. Phytochemistry Reviews . [CrossRef] 